\title{
Eigenvalue Selection and Development Control of Rural Tourism: a Case Study of Raghurajpur, an Artful Village in Puri
}

\author{
Anjali V. Narad ${ }^{1}$, Priya Raut ${ }^{2}$ \\ ${ }^{1}$ Assistant Professor,Radhikatai Pandav Institute of Architecture,Nagpur ,R.T.M.Nagpur University,India \\ ${ }^{2}$ Associate Professor, Shri Datta Meghe College of Architecture, Nagpur, R.T.M. Nagpur University, India
}

\begin{abstract}
In India we found an endless, living vibrant tradition of crafts and culture, while Odisha is a diversified state with a variety of tourist attractions and amenities. The Odisha culture reside in villages and having high potential for art and cultural growth in terms of tourism .Tourism growth potential can be harness as a strategy for rural tourism development. The concept of rural tourism should be used for Odisha and their villages which constitute rich cultural heritage, magnificent architectural buildings \& monuments. This research paper discribes the concept and development of rural tourism in odisha, with the case study of Raghurajpur. Rural tourism is a multifaceted destination because of its eco, ethnic, farm, cultural, historical importance. This paper also deals with accentuating artisan beauty of Raghurajpur village and various methods by which we can make it sustainable to with proper understanding between the tourist and local people to participate in tourism development of Puri in Orissa.
\end{abstract}

Keywords: Tourism, Tradition, Culture, Artesian Village, Heritage Tourism

\section{Introduction}

"It shall be the duty of every citizen of India to value and preserve the rich heritage of our composite culture" Fundamental Duties, 51 -A, Constitution of India.

Vibrancy is the essence in Indian culture which is worldwide reached. While majority Indian population contributes to agriculture. In the history, research shows that the Caste system had sustained crafts production because of the social serenity of the artisan and the demand for crafted objects being restricted to local demands.

In any Indian traditional villages like Raghurajpur, there lies a deep interdependency between artisans and the society. Most of the Odishian villages are engaged in making articles of decoration required for festivals in temples and households which has not only provided them their daily wages but also extended an opportunity for artistic expressions. It may be the articles like tie and dye textile or appliqué work, terracotta, lacquer or brassware, filigree ornaments or pattachitra paintings etc. All these skills made the daily life of Odishian people not only artistic but also provide them avenues for business in other parts of the country as well as abroad too. Raghurajpur is one of the high-flying name which belongs to odisha and has the manifestation of traditional art and craft culture. This place is emerge as a well known name for artisan village in india.

\section{$\underline{\text { Rural Tourism }}$}

Rural Tourism has emerged as a new Concept in rural areas which can bring economic and social benefits to the society through rural people skills. This concept has been already examined in the developed countrise and proved their successful outcome. The villages in India have so many ways to cater the needs of the tourists. The rural people with its culture, tradition, arts, handicrafts, scenery, landscape can allure the tourists despite of its taste, perceptions \& attitudes.
As per Gannon, Rural Tourism"e covers "a range of activities provided by farmers and rural people to attract tourists to their area in order the generate extra income for their business." Any form of tourism that portray the rural life, art, culture and heritage at rural locations, so that it will be benefiting the local community economically and socially as well as provide relation between the tourists and the local people for a more augment tourism experience can be termed as rural tourism.

\section{Importance of 'Rural Tourism”' in Odisha}

The biggest advantage of rural tourism is its ability to generate money which can provides huge opportunities to develop positive economical growth for locals and their communities.

The concept of rural Tourism is fruitfully helpful \& effective for a state like odisha where a maximum population lives in villages. Different villages have different types of tourism resources, which are disperse in the entire state. (The Zamindars houses, Handicrafts, folk- lore \& Folk music etc.)Rural tourism can check \& can stop the flow of people to migrate in Cities. The moderate amflification of cities \& urbanizations some time captivate the people to resettle from rural to urban areas. Rural tourism can be one of the important outlooks, which can provide a key to this problem. Tourism growth can be harness as a method for Rural Development.

The drift of "Urbanization" has led to falling income levels, lesser job opportunities in the rural areas. Rural tourism is the only solution to this problem. In many parts of Odisha the rural economy is in despair due to the increase in input costs and decrease in income.

\section{Significance of the Study}


According to the 10th Five Year Plan, plunge has been given to promote village tourism as the key tourism product to extend tourism and its socio-economic profit to rural areas. For proper establishment of infrastructure in rural areas, a variety of actions have been undertaken like development of surroundings of the village which include landscaping, development of parks, fencing and compound wall, improvements of roads within the Panchayat limits, lighting in the village, provision for improvement in solid waste management and sewerage management. Eco-friendly modes of transport for moving within the tourism zone directly related to tourism. Along with that, restoration of the monuments, reception centers, tourist accommodation and other activities are part of the tourism.

\section{Raghurajpur An Artisan Village, Puri}

Raghurajpur, a small village in Puri district, takes up an exceptional place in the cultural map of Indian tourisum. The village is occupied by artisans producing absolute poetry on pieces of treated cloth, dried palm leaf or paper.

This magnificent artisan village Situated on the southern bank of river Bhargavi and surrounded by coconut, palm, mango, jackfruit groves and other tropical trees. Raghurajpur has a pleasant beauty. The village runs from east to west with houses arranged in two neat rows, facing each other. At the centre, runs a line of small temples and the lone Bhagabat Tungi, the community meeting place of the villagers. The temples are dedicated to the lords, Radha Mohan,Gopinath, Raghunath, Laxminarayan, Gouranga, and to the village goddess, Bhuasuni.

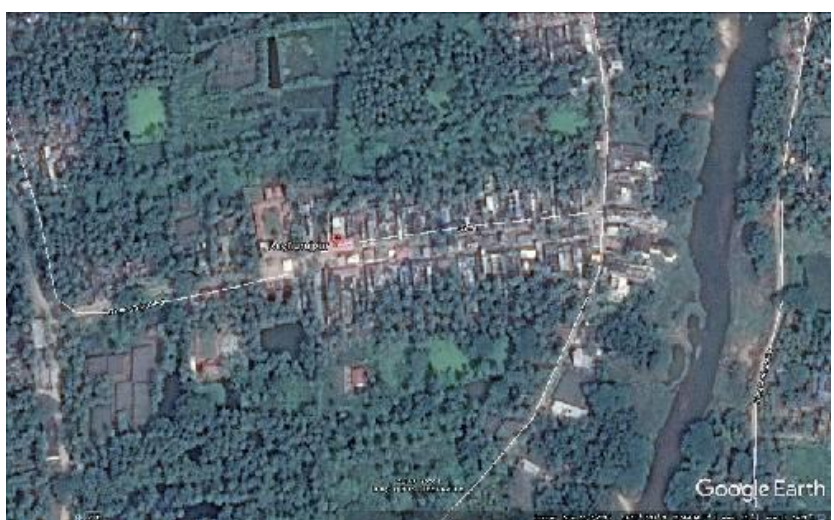

Figure 1: location of the Raghurajpur village(Source:(map data 2014 Google)

To reach the village one has to get down at Chandanpur bus stop, which is about $10 \mathrm{~km}$ from Puri and $50 \mathrm{~km}$ from Bhubaneswar on N.H.No.203 connecting Puri and Bhubaneswar. Chandanpur to Raghurajpur its about $1.3 \mathrm{~km}$ picturesque road. Entire village is shaded by coconut-palm trees. Village is moderately different from other villages of the Odisha State. It has its own identity in all the sence its overall beauty and most talented articians residing there. Thousands of tourist including foreigners visit the village around the year. Tourist didn't come here to see a typical Odishan village from close station but to see and enjoy the rich traditions of Odisha arts and crafts at one place.

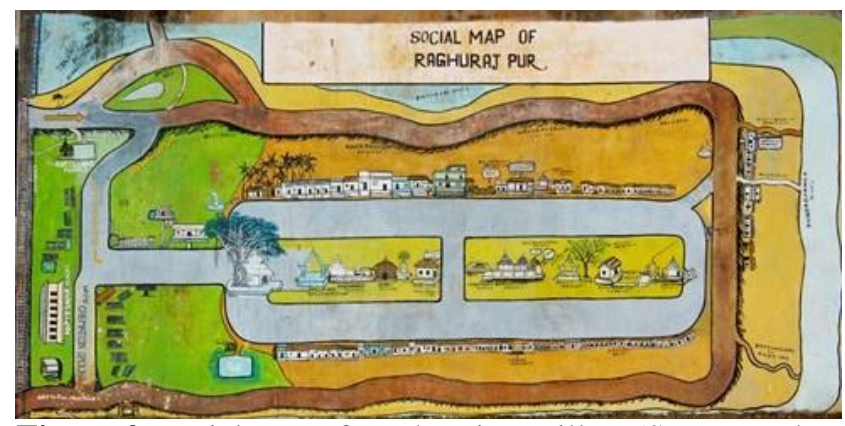

Figure 2: social map of Raghurajpur village(Source:author courtesy )

The village has a community of artisans, who create different varieties of handicrafts objects such as Pattachitra paintings, palm leaf engravings, stone carvings, paper mask toys and masks, wood carvings, wooden toys, cow dung toys and tusser paintings. This place is one of the rarest in India where we finds fusion of many arts at one place. This is also the one and only village in India, where each family member is engaged in one craft or another. All over 103 households found and having 311 artisans in the village. Many of them are winners of National Awards. Painting work found unique and some of them are finest pieces of work. Pattachitra paintings are found oldest amongst all the work.

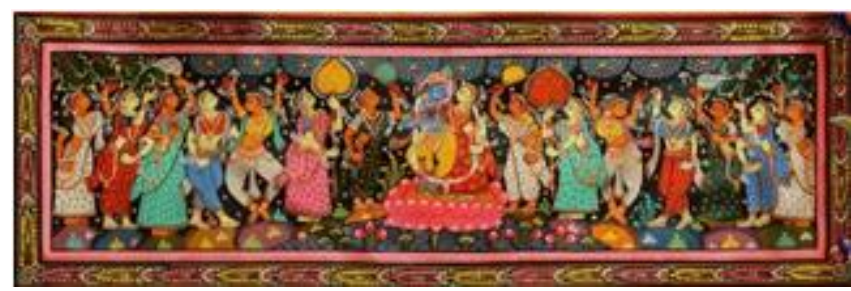

Figure 3: Pattachitra paintings of Raghurajpur village (Source: author courtesy)

There are several centers of this art like Puri, Parlakhemundi, Champamal (Sonepur), Athgarh and Dinabandhupur (Dhenkanal). Usually, the lane in which these painters or chitrakaras live is called Chitrakar Sahi. Although there are several centres of patapaintings in Odisha, it is Raghurajpur, which is famous for this unique art.
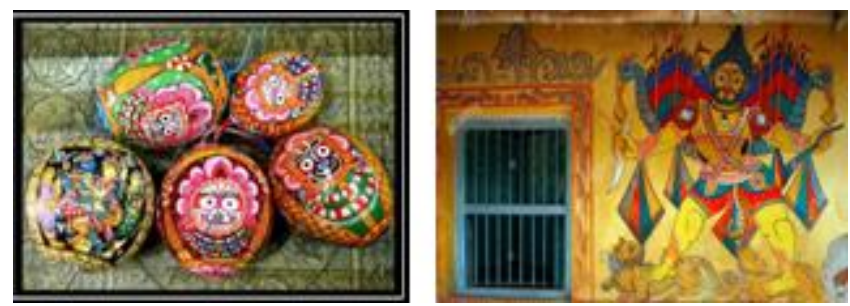

Figure 4, 5: Paintings on wall and coconut balls

During the period of Anasara, the fortnight following the fullmoon day, three Patis painted by Chitrakaras are placed on the sighasana inside the main temple. The chitrakaras are also called to execute colourful paintings on the three chariots for the Car Festival. 


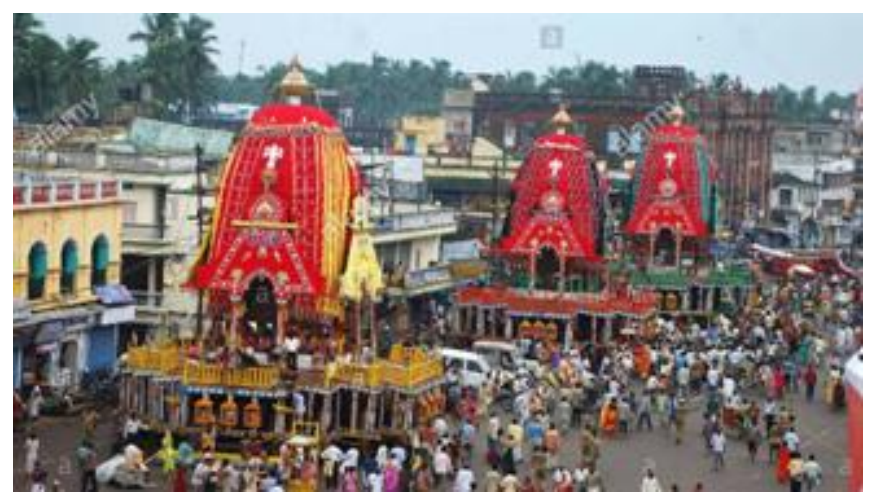

Figure 6: Three chariots for the Car Festival.
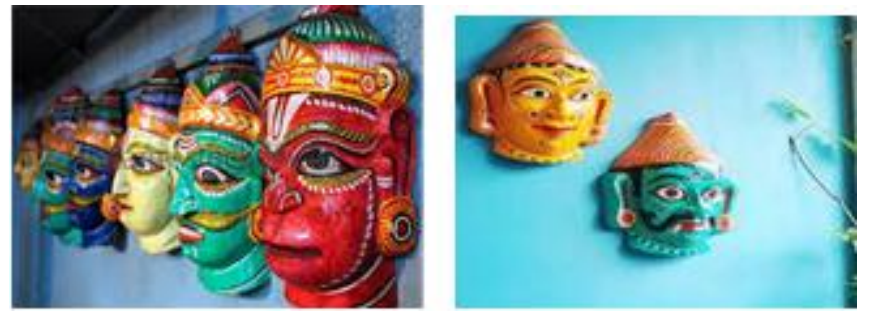

Figure 7, 8: Art on wall and paper mask toys

Very special feature about Raghurajpur village is that it has been selected by INTACH to revive the ancient wall paintings of Odisha. The work has already been completed and now the village looks like a living museum of paintings. Odisha Tourism and Ministry of Tourism, Government of India have identified this village for development of Rural Tourism and working on this village to give its correct place in cultural and tourist maps of the India. Hon'ble Union Minister of Tourism and Culture, already declared that this village would be developed as a model for rural tourism in India.

For further development of artisans special area allotted for workshop for the students and interested tourist. Many Architecture and fine arts students from all over the world visit this place to see and learn the unique art and culture.

\section{Glimpses of Raghurajpur}

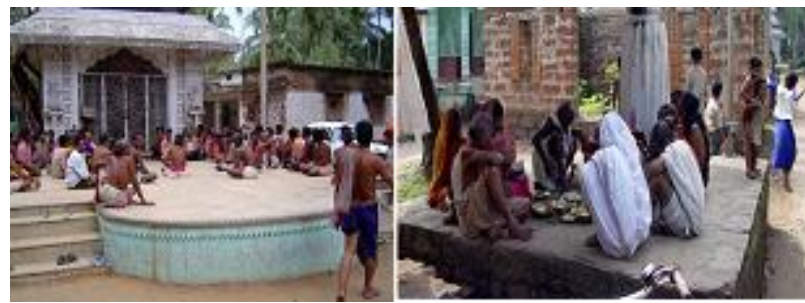

Figure 9, 10: Social spaces for Regular village meetings
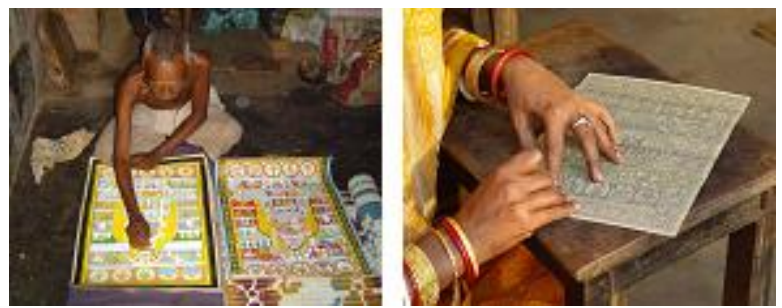

Figure 11, 12: Famous Pattachitra Paintings

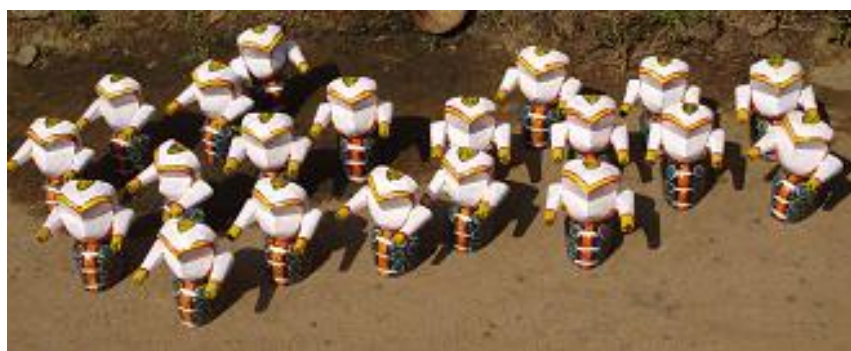

Figure 13, 14: Wooden religious figures made out of wood
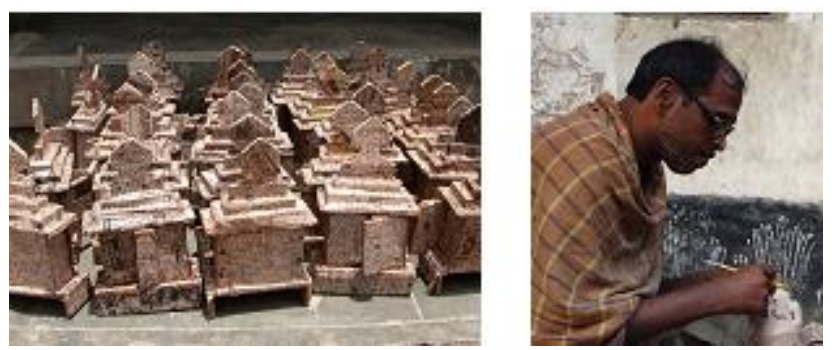

Figure 15, 16: Paper-mache and its making

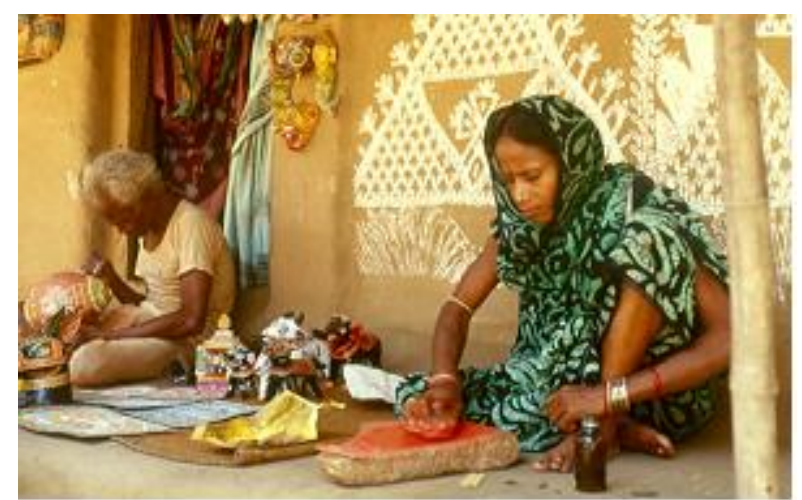

Figure 17: Paintings on coconut kernel

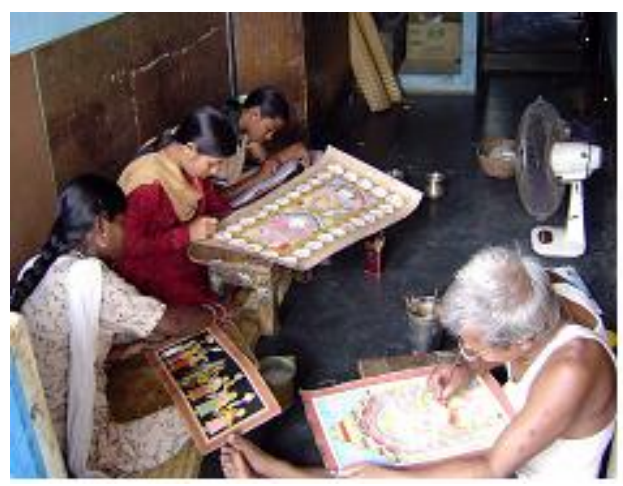

Figure 18: Extension of artist studio

\section{Conclusion}

Rural tourism in Odisha has great prospect future, since its not only provides natural elements of beauty but also the native local traditions, customs and foods. Direct experience with local people can be a unique selling proposition to magnetize tourists. The Raghurajpur village is rich in intangible living heritage -art, crafts and dance traditions, but they had all vanished feasibility in recent years. It could be a major sustainable revenue generating project for rural development. The short term and long-term planning implementation and monitoring are crucial in avoiding damage to rural areas. Environmental management, local involvement, sound legislation, sustainable marketing, 
and realistic planning are essential for development of rural tourism. The government should promote rural tourism to ensure sustainable economic development and positive social changes in villages like Raghurajpur.

\section{References}

[1] Bulter R., \& Clark, G. (1992). Tourism in Rural Areas: Canada and U.K., Contemporary Rural Systems in transition. Economy and Society Wallingford, Vol. 2, p. 175.

[2] Gannon A. (1990). Rural tourism as a factor in rural community Economic development for Economies in transition, Journal of Sustainable Tourism, 1 (1\&2) p. 51-60.

[3] Kumar Pro. Kapil (2001). Tourism Impacts, MTM-10, IGNOU text book, New Delhi.

[4] Lane, B. (1994). What is Rural Tourism, Journal of Sustainable Tourism, Vol. 2, P. 7-12.

[5] Heritage Conservation for Poverty Alleviation INTACH's Initiatives in Raghurajpur, Orissa by SK MisraChairman, INTACH, New Delhi

\section{Author Profile}

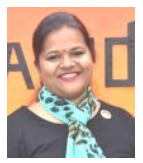

Ar.Anjali V.Narad is currently working as Assistant professor In Radhikatai Pandav Institute Of Architecture, Nagpur, India. Before joining the college she has been worked as Assistant professor In K.I.T.S Ramtek for over four years. Her experience in the construction industry, especially as an Interior Designer. She is an active researcher and has published a number of research papers in National \& International Conferences. Her current research interests include, Sustainable Development, Vernacular Architecture. In addition, she has also enthusiastically contributed to the relevant professional institutions and the community.

Ar.Priya Gupta is currently the Assistant professor In Before joining the college she has been worked as Assistant professor in Radhikatai Pandav Institute Of Architecture, Nagpur, India \& HCATP Jabalpur for over five years. contributed her experience in civil as well as architecture. She did her masters in Architecture Education from Nagpur, she is an active researcher and has published number of paper in architectural magazine and conferences. Her interest areas include experiment \& explore in the field of Architecture education.. In addition, she has also enthusiastically contributed to the relevant professional institutions and the community. 